Review article

\title{
Improving the prediction of environmental fate of engineered nanomaterials by fractal modelling
}

\author{
S. Avilov ${ }^{\text {a }}$, L. Lamon ${ }^{\text {b }}$, D. Hristozov ${ }^{\text {b }}$, A. Marcomini ${ }^{\text {b,* }}$ \\ a Department of Solid State Physics and Nanostructures, Voronezh State University, Universitetskaya pl., 1, 394006 Voronezh, Russia \\ b Department of Environmental Sciences, Informatics \& Statistics, University Ca' Foscari of Venice, 30172 Mestre (VE), Italy
}

\section{A R T I C L E I N F O}

\section{Article history:}

Received 7 June 2016

Received in revised form 24 November 2016

Accepted 27 November 2016

Available online 15 December 2016

\section{Keywords:}

ENMs environmental fate

Kinetic models

IFS fractals

Fractal modelling

Hierarchal symmetry

ENM structural classification

\begin{abstract}
A B S T R A C T
A critical analysis of the available engineered nanomaterials (ENMs) environmental fate modelling approaches indicates that existing tools do not satisfactorily account for the complexities of nanoscale phenomena. Fractal modelling (FM) can complement existing kinetic fate models by including more accurate interpretations of shape and structure, density and collision efficiency parameters to better describe homo- and heteroaggregation Pathways to including hierarchical symmetry concepts and a route to establishing a structural classification of nanomaterials based on FM are proposed.
\end{abstract}

(c) 2016 Published by Elsevier Ltd.

\section{Contents}

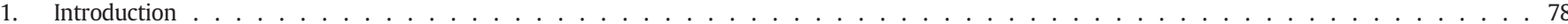

2. Towards the incorporation of fractal modelling in transformation and transport kinetics models $\ldots \ldots \ldots$

2.1. Existing modelling approaches in ENMs environmental fate and transport . . . . . . . . . . . . . . . . . . . . . . . 79

2.2. FM applied to aggregation modelling . . . . . . . . . . . . . . . . . . . . . . . . . . . . . . 79

2.3. Introduction of a fractal classification of ENPs aggregate structures . . . . . . . . . . . . . . . . . . . . . . . . 80

3. Steps to include FM in ENM environmental kinetic models . . . . . . . . . . . . . . . . . . . . . . . . . . . . . . . . . . 81

3.1. Step 1. Collecting empirical data and building the fractal model . . . . . . . . . . . . . . . . . . . . . . . . 81

3.2. Step 2. Linking physico-chemical characteristics to the fractal model . . . . . . . . . . . . . . . . . . . . . . . . . . . . . . . 81

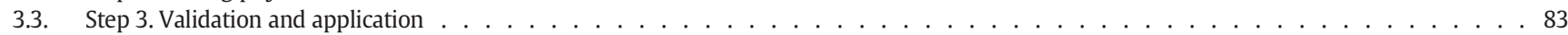

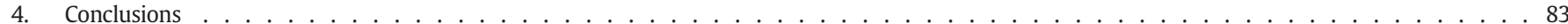

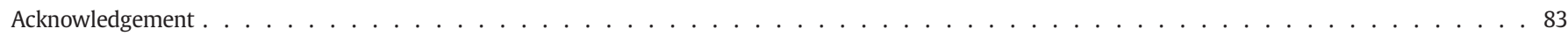

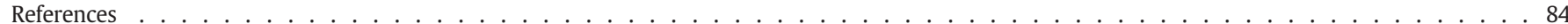

\section{Introduction}

Nanotechnology is a field of science and technology involving the design, production and use of structures at the nanoscale (SCENIHR, 2006). Due to the broad applicability of the unique physicochemical characteristics of engineered nanomaterials (ENMs), a variety of nanoenabled applications in electronics, nutrition, cosmetics, medical

\footnotetext{
* Corresponding author.

E-mail address: marcom@unive.it (A. Marcomini)
}

drugs, food and agriculture, textiles, and energy have been introduced (Hendren et al., 2011; Piccinno et al., 2012). There is concern, however, that the above technological progress may also introduce environmental and human health risks (Klaine et al., 2008). The environmental risk assessment (ERA) used for chemicals is considered as the pertinent approach to assess and quantify environmental risks posed by ENMs (Hristozov et al., 2013; Stone et al., 2014). It is a four-step process, consisting of: 1) hazard identification, 2) effect assessment, 3) exposure assessment, and 4) risk characterization (Van Leeuwen and Vermeire, 2007). Exposure assessment is a fundamental step in the ERA, and 
consists of the calculation of Predicted Environmental Concentrations (PECs). As recommended by the Registration, Evaluation, Authorization and Restriction of Chemicals (REACH) Chemical Safety Assessment guidance, dynamic or steady-state multimedia mass balance models (MMMs) are commonly applied to estimate PECs in different compartments. This is due to the fact that in the case of ENMs monitoring information is scarcely available and analytical protocols are still under development (Hassellov et al., 2008; Ono-Ogasawara et al., 2009; Tiede et al., 2010; Tuoriniemi et al., 2012). Physical processes of agglomeration, sedimentation and re-suspension are considered relevant in modelling ENMs environmental fate (Chekli et al., 2015; Meesters et al., 2013; Praetorius et al., 2013, 2012; Quik et al., 2011) but the accuracy of the estimations of these parameters is not satisfactory enough to get realistic predictions (Garner and Keller, 2014).

Meesters et al. (2014) have stressed the relevance of modelling hetero-agglomeration kinetics of ENMs in the water media. A comprehensive analysis of factors affecting ENMs fate, including collision frequency and attachment efficiency is given but the lack of methods capable of predicting structural and surface properties of nanoaggregates is stressed.

To better represent the complexity of nanoaggregate structures in the environment efforts were made to include Fractal Dimension (FD) into the ENMs kinetic models (Arvidsson et al., 2011; Chowdhury et al., 2013; Neil et al., 2016; Praetorius et al., 2012). Nanoparticle (NP) aggregates are less dense material packings in comparison to monocrystals and form structures that are difficult to describe by means of Euclidian geometry. The incorporation of fractal (fractional) dimension demonstrates that the material self-organizes in patterns that cannot fill the granted 3-D space compactly and how much space is truly occupied. However, it does not give insight on the phenomenological processes governing aggregation or on specific morphological properties of particles. Fractal modelling (FM) is often applied to enhance kinetic models (Saunders and Plane, 2006; Sithebe and Nkhalambayausi Chirwa, 2016) but no classification of NMs based on fractal properties has yet been proposed.

The goals of this paper is to identify how limitations of existing approaches used for the predictions of ENMs fate may be overcome with the help of FM. Specifically, this paper will (i) present the existing methods employed for ENMs exposure and fate modelling, (ii) introduce basic concepts and methods of fractal geometry and (iii) describe the pathways of applying FM to obtain more realistic predictions of ENMs environmental behaviour.

\section{Towards the incorporation of fractal modelling in transformation and transport kinetics models}

\subsection{Existing modelling approaches in ENMs environmental fate and transport}

Modeling methodologies applied so far to ERA consider mainly Mass Flow Analysis (MFA). Mueller and Nowack (2008) developed the first material flow model considering releases of ENMs from products in different lifecycle stages to estimate PECs for nanoscale $\mathrm{Ag}, \mathrm{TiO}_{2}$ and Carbon Nanotubes (CNTs) in the Swiss air, soils and waters. Later this approach was applied to budgeting environmental distribution of ENMs in Denmark (Gottschalk et al., 2015). Further developments overcame the simple approach by addressing input uncertainties for a holistic spectrum of possible scenarios through a probabilistic model involving Monte Carlo, Bayesian and Markov Chain analyses (Gottschalk et al., 2009, 2010). In Keller and Lazareva (2014) this modelling approach is applied to predict region-specific environmental concentrations. The models incorporate input parameters such as production and consumption volumes, fate pathways quantified though transfer coefficients. However, it is stressed that relevant factors of engineered nanoparticles' (ENP) size, structure, chemical activity and evolution in the environment are not taken into consideration. To model such parameters, new mechanistic approaches (Maggi, 2009; Sithebe and Nkhalambayausi Chirwa, 2016) that would take specific physical and chemical nanoscale phenomena (Bishop et al., 2009; Walker et al., 2010a) into consideration are needed.

Kinetic models were applied in Quik et al. (2011) to introduce dissolution and sedimentation rate constants seeking a step-by-step environmental fate simulation. This approach represented a move toward defining exposure in the aquatic environment but did not provide the possibility to describe the transport of ENMs and accordingly predict their behaviour in different media. Arvidsson et al. (2011) proposed the use of kinetic laws by Smoluchowski (1917) and Friedlander (2000) along with the inclusion of sedimentation, perikinetic and ortokinetic agglomeration caused by shear flows and differential settling caused by sedimentation into account.

In later work, Praetorius et al. (2012) added ENM interactions with suspended particulate matter (SPM) to the model. Definitions for rate constants were derived from Elimelech et al. (1995a). Aggregation with environmental colloids is more frequent than interaction between the pristine particles, and the lack of a systematized approach to describing physical aspects of the phenomena responsible for these interactions makes accurate fate predictions a complicated task (Docter et al., 2015, Jun et al., 2016).

\subsection{FM applied to aggregation modelling}

The first steps to account for the shortcomings related to shape and topology were made by including fractal dimension into the kinetic equations as a statistical parameter (Arvidsson et al., 2011; Praetorius et al., 2012). Wiesner (1992) and Elimelech (1995a) were among the first to introduce FD-dependent floc density when modelling nanoand micro-scale aggregation. According to Wiesner (1992), the mass density $\rho$ of a sphere of radius $r$ within a floc is a power function

$\rho(r) \sim r^{\left(D_{f}-3\right)}$

where fractal dimension $D_{f}$ can take values from 1 to 3 . This shows that the material occupies less volume within the Euclidian space than an entirely compact object such as a coalesced sphere. The value of fractal dimension is obtained with the same equation that gives the dimension of objects in the Euclidian space. When an object is split into $N$ equal parts that are $r$ times smaller than the original object the dimension $D$ of the object is defined as:

$D=\frac{\log N}{\log (1 / r)}$

$D=2$ for a compact plane, and 3 for a compact cube. In the case of less dense objects for a large enough $r$ dimension would take fractional values, accounting for the space not occupied by material, and would be called fractal dimension (FD) (Crownover, 1995). It is also used as a measure of complexity for structured non-compact mathematical objects, especially those completely or partially self-similar at any scale of examination, called fractals (Mandelbrot, 1983). FM uses various iterative algorithms to build such complex structures.

The first methods applied to physical aggregation modelling were based on the concepts of the Diffusion Limited Aggregation (DLA), proposed by Witten and Sander (Witten and Sander, 1981; Frenklach et al., 2009; Köylü et al., 1995; Pippa et al., 2013) where particles moving in Brownian motion stick together in case of collisions (Fig. 1). The process is chaotic, however by modifying the rules of attachment and disattachment the FD dimension can vary (Inci et al., 2014).

Deterministic fractals with a strictly defined symmetry are an alternative to DLA. The idea of using self-similarity and self-affinity to model nanosystems has been presented by Mandelbrot (1986). In the mentioned work an object is defined as self-affine if it consists of non-overlapping parts that can be represented by applying a linear affine 


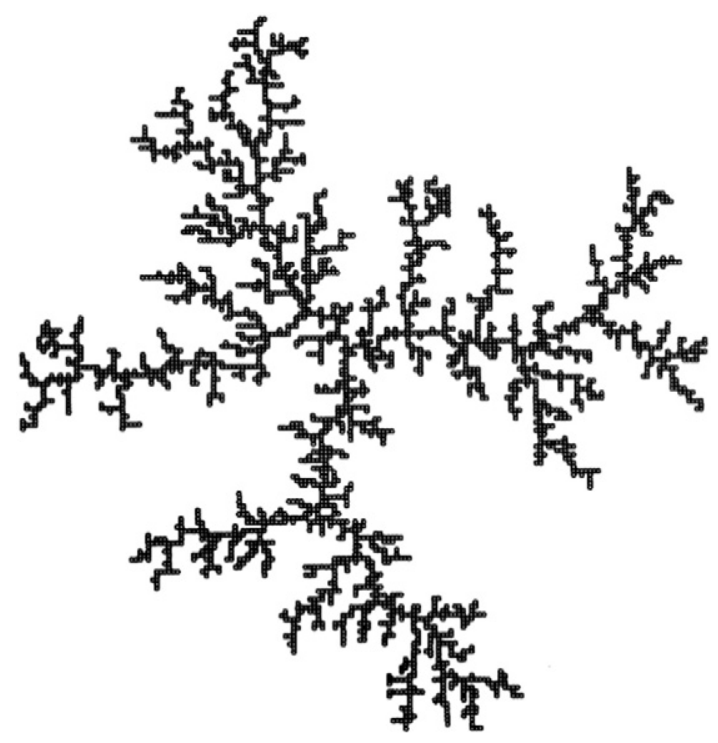

Fig. 1. A DLA model of a 3000 particle aggregate on a square lattice. Courtesy of Witten and Sander, 1981.

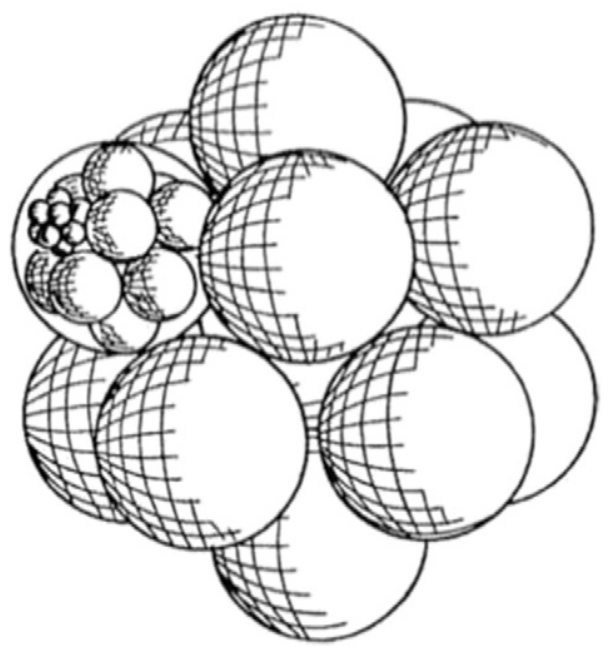

Fig. 2. A conceptual representation of a self-similar and self-affine hierarchical object. Courtesy of Shevchenko and Mackay (2011).

a

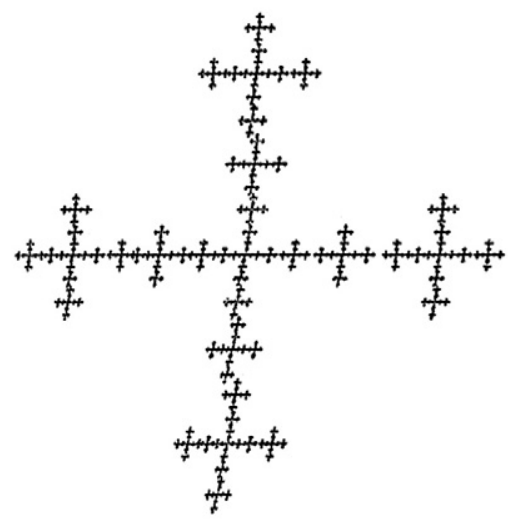

transformation function (combination of translation, scaling and rotation operations) to other parts of this object (Fig. 2).

As shown in methodological works of Barnsley on the Iterated Functions System (IFS) method (Barnsley, 1988; Barnsley and Demko, 1985; Nikiel, 2007) the recursive process of applying such transformations from a predefined set to a primary particle builds traces of fractal objects with a desired symmetry (Fig. 3a).

Fractals (Fig. 1, 3a) are inherently characterized by a fractal dimension. The common method to calculate FD of fractal models is the BoxCounting method when the studied object is repeatedly covered with sets of boxes, and each set is defined by the size of the box's edge, $r$. The number of boxes $N$ necessary to cover the object is plotted as a function of $r$ and the slope $S$ of the $\log (N(r)) / \log (r))$ graph gives the FD, in this case called box fractal dimension (Jelinek et al., 2013; Feder, 1988).

The relevance of fractals for the nanoscale is linked to the morphology-specific physico-chemical properties that distinguish them from chemicals and before a NP dissolves (Dale et al., 2013) colloidal aggregation should be accounted for (Cai et al., 2017; Wang et al., 2003). By now fractal dimension is included in various NM studies, e.g. evolution studies of nanoscale $\mathrm{TiO}_{2}$ in aquatic media (Chowdhury et al., 2013; Godinez and Darnault, 2011; Loosli et al., 2013; Xu et al., 2014), studies of fullerite nanoparticles in electrolyte solutions (Meng et al., 2013). Fractal image analysis methods were used to classify organic and inorganic structures (Kimori et al., 2011; Kong et al., 2014; Papanicolaou et al., 2012; Smith et al., 1996, Neil and Curtis, 1997). Neil et al. (2016) studied fractal structures of iron oxide nanoparticles aggregated with natural organic matter and arsenate to better predict the sedimentation rates in the environment. The oil industry recently adopted fractals to enhance environmental kinetics models (Mohammadi et al., 2016; Sterling et al., 2005). Fractal parameters are used to realistically mimic nanosystems in biology, medicine and pharmaceutical sciences (Graham and van Ooyen, 2001; Jayasuriya et al., 2013; Pippa et al., 2013; Captur et al., 2015; Kaandorp, 1994; Karperien et al., 2013).

\subsection{Introduction of a fractal classification of ENPs aggregate structures}

The last mentioned work of Karperien et al. (2013) is focused on developing a classification of neuron cells based on their fractal shape. This approach is feasible as such representations of cells require little amounts of hard-drive storage (fractals are represented by functions that can be written in a text file) and give a comprehensive description of the cell's structure.

To develop such a classification for ENMs, a structure analyzing method should be applied. One of the first applications of fractals was image compression, and many specialized image processing methods

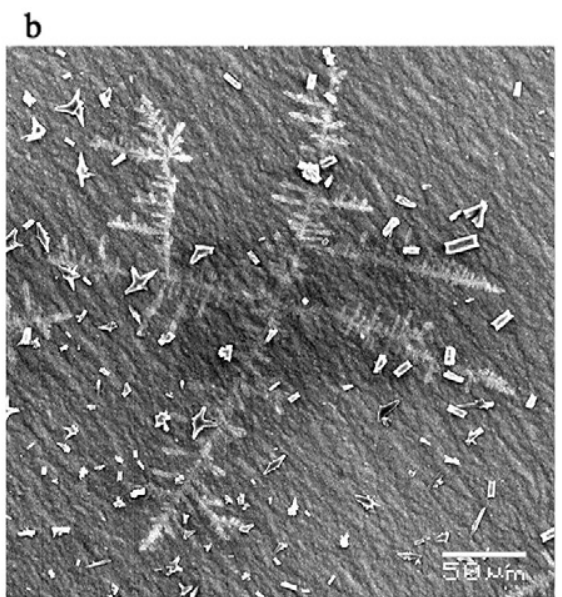




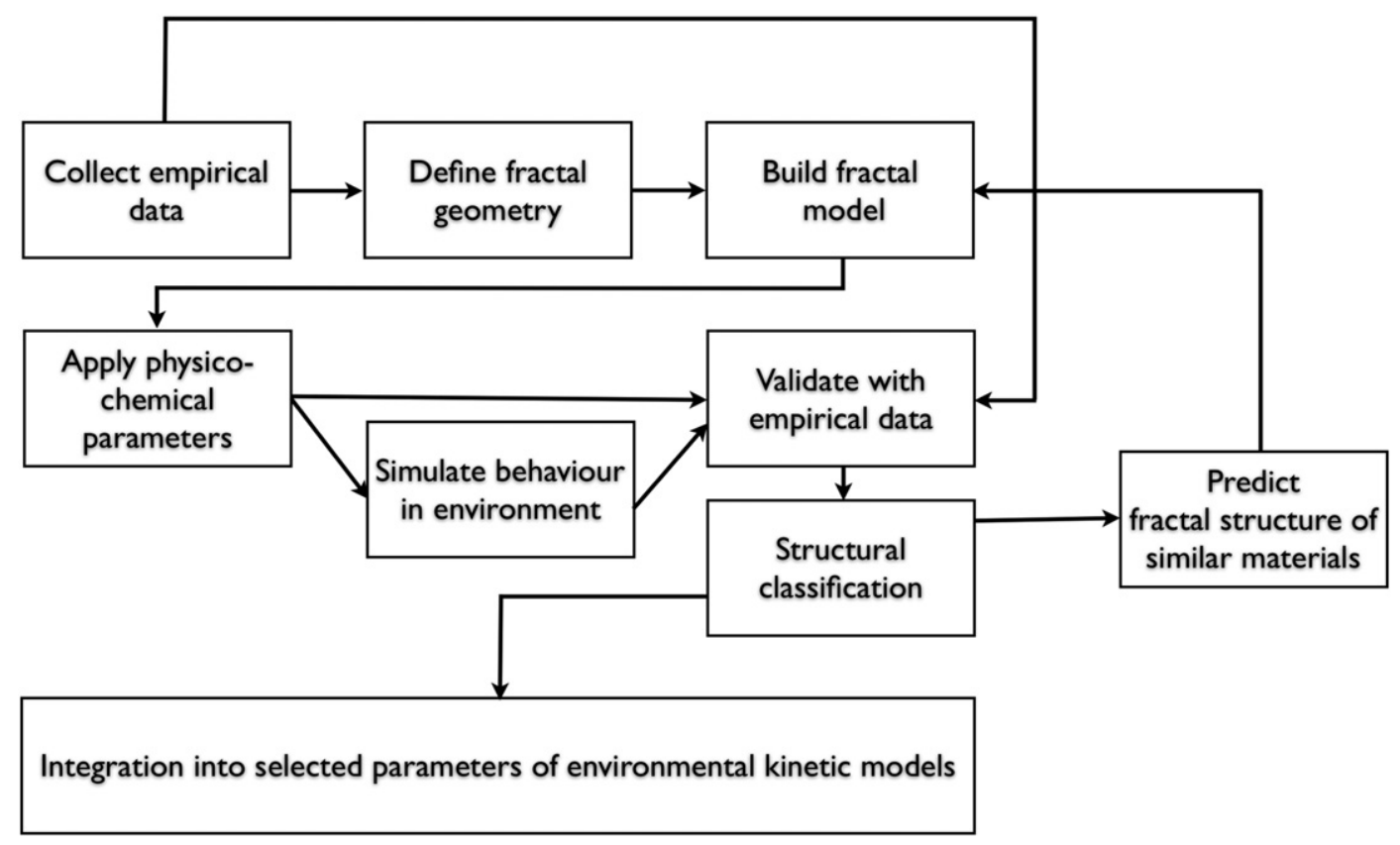

Fig. 4. A schematic of the proposed route for the integration of fractal modelling into environmental kinetic models.

were developed (Ho Moon et al., 1999; Papanicolaou et al., 2012; Smith et al., 1989; Xiaoqing et al., 2013). A good example of a well applied fractal classification are fingerprint databases (Lin, Chen and Gaing, 2010). The process of building a fractal model is rapid as it is based on recursive algorithms. For instance, an array of 50000 pixels requires less than 8 seconds to be built using the IFS method and rendering algorithms for various FM methods are constantly optimized for productivity (Gröller, 1994; Karam and Nakajima, 2001; Martyn, 2010).

These considerations predict a possibility to develop and apply a quantitative structure classification of nanomaterials to include in kinetic transport and transformation models used in environmental fate modelling. A schematic representation of the predicted steps is given in Fig. 4. Further Table 1 focuses on how various parameters used in existing environmental models (Dale et al., 2015) could benefit from FM and nearest steps required for an integration are presented in more detail in Section 3.

\section{Steps to include FM in ENM environmental kinetic models}

In this section nearest steps required to fulfill the tasks resulting from the schematic approach shown in Fig. 4 are presented.

\subsection{Step 1. Collecting empirical data and building the fractal model}

The lack of quantification methods for creating a nanoaggregate morphology classification was stressed by Pippa et al. (2013) and Papanicolaou et al. (2012). Currently technology provides powerful methods to study material structures. For example, Fig. 5a shows a Cryo-TEM tomography reconstruction of an organic nanoparticle. This 3-D image can be analyzed to find a characteristic symmetric algorithm.

The Polar IFS and the Generic Programming image-decoding methods are capable of solving the task of defining an IFS for a given image (Collet et al., 2000; Hart, 1996; Hart et al., 1997). An electron microscopy image of an aggregate can also be reduced to its outlines to simplify the analysis (Kimori et al., 2011; Du et al., 2012; Ferreiro et al., 2013; Hagerhall et al., 2004). The symmetry types can be extracted from new geometrical theories developed for new tasks in material engineering (Lord et al., 2006; Shevchenko and Mackay, 2011; Ivanov and Talanov, 2013; Bokeloh et al., 2010).

In the given example (Fig. 5a), the symmetry is icosahedral and a fractal model with a corresponding symmetry can be created. In the self-affine approximation the model (Fig. 5b) represents the real particle's structuring.

It was shown that NMs do not maintain ideal symmetrical structures, and form semi-chaotic structures (Mandelbrot, 1992; Walker et al., 2011). However, taking into account the appearance frequency of polyhedral objects in the nanoscale world (Kowalczyk et al., 2011; Walker et al., 2010a, 2010b) the deterministic FM approaches (Karperien et al., 2013; Avilov et al., 2014) can be considered applicable for aggregation modelling. The IFS fractal generation process is based on a chaotic algorithm that allows for variability and provides realistic uniqueness to every modelled object while sustaining a general symmetrical pattern.

The turtle graphics (L-system) method that builds branching systems according to a pre-defined rule (Ju et al., 2004; Crownover, 1995 ) could be an alternative to the IFS models. It was found applicable in the modelling of neuron structures (Karperien et al., 2013).

\subsection{Step 2. Linking physico-chemical characteristics to the fractal model}

Environmental fate and exposure modelling of ENMs deals with an abundance of variables and the aim is to find simple enough approaches that would streamline this complexity (Sani-Kast et al., 2015). However even given the possibility to model complex fractal structures it is necessary to functionalize them with relevant physical and chemical properties.

The DLVO theory is used in MMMs to addresses the colloidal stability through the description of the interactions experienced by a nanoparticle when approaching another nanoparticle or a collector surface. The classical DLVO theory (Petosa et al., 2010) takes only van der Waals and electrostatic interactions into account, whereas the revised version of the theory additionally considers other specific interactions that are relevant when dealing with NMs, such as magnetic forces, steric 
Table 1

The table reports definitions of the descriptors used in MMMs and improvements that can be introduced to these descriptors by FM.

\begin{tabular}{|c|c|c|}
\hline $\begin{array}{l}\text { Descriptors relevant for ENMs fate } \\
\text { modelling }\end{array}$ & Approaches from MMMs & Predicted FM improvements \\
\hline Particle shape & $\begin{array}{l}\text { Particles are assumed to be spherical (Arvidsson et al., 2011; Liu and Cohen, 2014; Praetorius et } \\
\text { al., 2012). }\end{array}$ & $\begin{array}{l}\text { Aggregates are to be represented as complex self-similar hierarchical deterministic symmetric or } \\
\text { chaotic objects (Gmachowski, 2002; Mandelbrot, 1992). }\end{array}$ \\
\hline Density & $\begin{array}{l}\text { Density is given as a constant. Fractal dimension is introduced as a coefficient to better represent } \\
\text { how aggregates occupy the given volume (Arvidsson et al., 2011). }\end{array}$ & $\begin{array}{l}\text { Floc density can be predicted from the morphology and FD of the fractal models. Pores and voids } \\
\text { that influence material density are often hard to study experimentally whereas they can } \\
\text { mathematically predicted with the use of fractal models (Pia et al., 2016). }\end{array}$ \\
\hline Particle size distribution & Describes how the size of the individual particles varies in a dispersion (Linsinger et al., 2012). & $\begin{array}{l}\text { Deterministic fractals predict stable characteristic sizes (Li et al., 2016) within modelled } \\
\text { structures basing on the chosen symmetry and hierarchical scaling properties. }\end{array}$ \\
\hline Initial particle shape and size & $\begin{array}{l}\text { Also mentioned as primary particle size (Praetorius et al., 2012) or crystallite size (Linsinger et } \\
\text { al., 2012), it corresponds to the diameter of the primary particles of which aggregates are } \\
\text { formed. }\end{array}$ & $\begin{array}{l}\text { Dots in fractal models can be replaced with monocrystal or amorphous particles of the initial size } \\
\text { and shape and corresponding physico-chemical parameters can be linked (ISO, 2012; Mishin et } \\
\text { al., 2015). }\end{array}$ \\
\hline Break-up and limiting size & $\begin{array}{l}\text { It is defined in (Elimelech et al., 1995b) as the maximum size of aggregates that depends on the } \\
\text { applied shear or energy dissipation and on "floc strength", also dependent on the attractive } \\
\text { forces between particles. }\end{array}$ & $\begin{array}{l}\text { Particle break-up can be predicted if forces responsible for aggregation and disaggregation (Li et } \\
\text { al., 2016; Bishop et al., 2009; Walker et al., 2011) are applied and binding forces between the } \\
\text { models and model parts are evaluated for both homo- and heteroagglomerates. }\end{array}$ \\
\hline Collision frequency & $\begin{array}{l}\text { It is a second-order rate constant, which depends on a number of factors, such as particle size } \\
\text { and transport mechanisms. Recent studies of particle functionalization in the environment } \\
\text { (Docter et al., 2015; Nasser and Lynch, 2016) stress the need to model physicochemical } \\
\text { properties in order to predict the real size of functionalized particles in the environment. }\end{array}$ & $\begin{array}{l}\text { In (Elimelech et al., 1995b) it is shown that the real volume occupied by aggregates tends to be } \\
\text { higher than that of the smaller particles summed together, thus a more realistic prediction of an } \\
\text { overall collision frequency can be achieved if fractal dimension and structuring are taken into } \\
\text { account when calculating particle volume. }\end{array}$ \\
\hline $\begin{array}{l}\text { Collision efficiency also referred to as } \\
\text { "sticking probability" or "stickiness } \\
\text { coefficient", } \alpha\end{array}$ & $\begin{array}{l}\text { It is defined as the fraction of collisions that are effective in agglomeration in (Elimelech et al., } \\
\text { 1995b). Praetorius et al. (2012) and by Quik et al. (2011) refer to it as attachment efficiency. }\end{array}$ & $\begin{array}{l}\text { Predictions of collision efficiency can be made if physico-chemical characteristics (Buffle et al., } \\
\text { 1998; Stolpe and Hassellöv, 2007) are applied to the modelled particle's surface area and binding } \\
\text { forces with other particles are calculated. The descriptor is used in DLA models (Witten and } \\
\text { Sander, 1981) as an input parameter. }\end{array}$ \\
\hline Composition & $\begin{array}{l}\text { The chemical nature of the materials. Recent studies show that the composition of the } \\
\text { eco-corona (Docter et al., 2014; Nasser and Lynch, 2016) is highly relevant for ENMs fate in the } \\
\text { environment. The protein corona may be considered the endpoint of ENPs within a live organism } \\
\text { (Canesi and Corsi, 2016), thus it is relevant for risk assessment. }\end{array}$ & $\begin{array}{l}\text { The surface chemistry properties of modelled nanoparticles are defined by the properties of the } \\
\text { comprising material (Lin, Tian, et al., 2010; Tuchin et al., 2014). Also the parameter of } \\
\text { composition can be used to predict self-assembly patterns (Walker et al., 2010b) if a } \\
\text { classification of NMs is produced, and vice versa. }\end{array}$ \\
\hline $\begin{array}{l}\text { Homo- and } \\
\text { Hetero-agglomeration/aggregation } \\
\text { rate constants }\end{array}$ & $\begin{array}{l}\text { Mentioned in (Arvidsson et al., 2011) as the rate constants governing agglomeration/aggregation } \\
\text { processes. Homo-agglomeration/aggregation refers to interactions of ENMs of the same type; } \\
\text { hetero-agglomeration/aggregation is the interaction of ENMs with natural colloids and SPM. }\end{array}$ & $\begin{array}{l}\text { A structural classification of ENMs and relevant environmental particles with linked } \\
\text { physico-chemical parameters can help develop an algorithm to predict the stability of } \\
\text { aggregation between nanomaterials and particles of similar and different composition } \\
\text { (López-López et al., 2006; Zhang, 2014; Smith et al., 2015). }\end{array}$ \\
\hline
\end{tabular}

rate constants
Particles are assumed to be spherical (Arvidsson et al., 2011; Liu and Cohen, 2014; Praetorius
al., 2012).

size (Praetorius et al 2012) or crystallite size (Linsinger

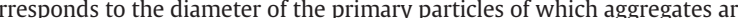
en particles.

(Docter et 1,$2015 ;$ Nasser and Ly

Collision efficiency also referred to as It is defined as the fraction of collisions that are effective in agglomeration in (Elimelech et al coefficient", $\alpha$

(1) hetero-agrlomeration/agregation is the interaction of ENMs with natural colloids and SPM 


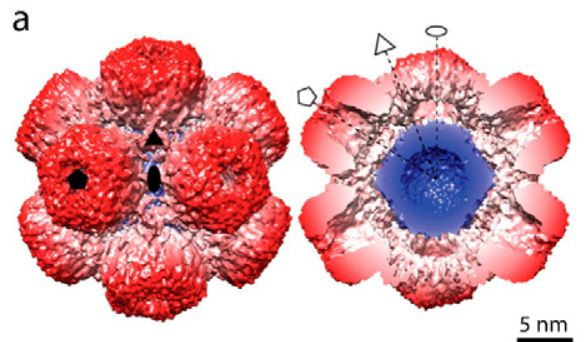

b

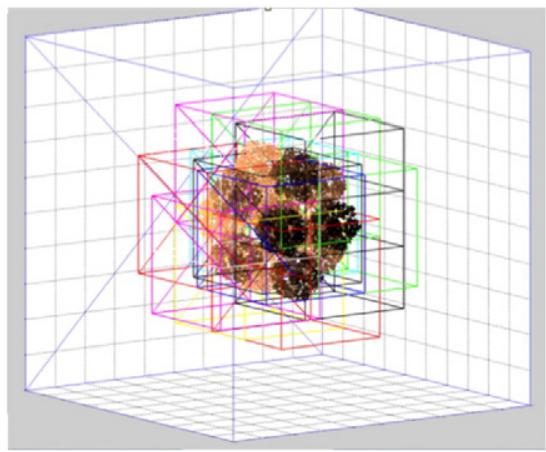

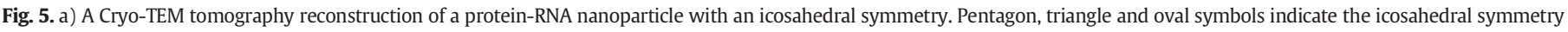

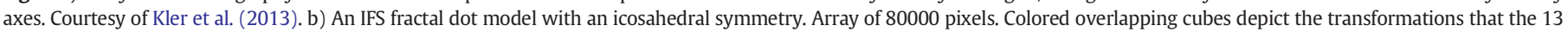
affine functions would apply to a larger primary unitary cube. Courtesy of Avilov et al. (2014).

interactions, and hydration forces (Grasso et al., 2002, Bishop et al., 2009; Healy and White, 1978; Lin and Wiesner, 2012).

Apart from the listed forces, there are other nanoscale-specific phenomena that are to be taken into consideration. For example, in (Browne and Grzybowski, 2011; Walker et al., 2013; Wang et al., 2011 ) it is shown how curvature of nanoparticles impacts electrical field distributions and the character of aggregation for various materials. Modelling by Tuchin et al. (2014) and Zhukalin et al. (2014) for carbon nanotubes shows that curvature at the nanoscale governs the redistributions of surface electric fields. Length- and diameter-dependent oscillations of the band gap and the subsequent altering of chemical properties for nanotubes were described in Ganin et al. (2014). More accurate shape considerations would improve predictions of chemical reactivity that can depend on surface energy for nanocrystals (Pal et al., 2007; Solla-Gullón et al., 2008; Xu et al., 2006).

The importance of the primary cluster morphology for aggregate evolution was shown in (Brasil et al., 2001) where a characteristic attachment angle parameter was defined for carbon soot particles. In the self-affine approximation, the relative arrangement of the affine reflections that form the fractal model can be chosen to correspond with the attachment angle. The initial monocrystals are then considered information carriers, responsible for the subsequent symmetrical aggregate self-assembly (Walker et al., 2010b, 2010a).

This approach to modelling hierarchical nanoparticles enhanced by physicochemical functionalization can be further applied to modelling heteroaggregation (Bitutskaya et al., 2013; Patil and Mann, 2008; Ruiz-Hitzky et al., 2008). Experimental evidence (Bitutskaya et al., 2013; Neil et al., 2016) shows that during the formation of hybrid nanosystems NMs can rebuild their structure depending on the intrinsic qualities (i.e. shape, dispersability) of the components. From the modelling point of view, it could be described as an integration of two (or several) characteristic symmetries and the formation of a qualitatively and quantitatively new symmetry. More specific experimental data is needed to develop and validate this approach to modelling hetero-aggregation. As shown in Bitutskaya et al. (2013) and Zhukalin et al. (2014) symmetry modifications can depend on component concentrations, pressure and other parameters.

\subsection{Step 3. Validation and application}

A created model should be verified with experimental data before incorporating it into a structural database and making predictions of structures of similar composition or properties.

In environmental kinetic models (Arvidsson et al., 2011; Praetorius et al., 2012) the volume and, subsequently, density of fractal aggregates are linked to FD, that itself is dependent on aggregate morphology. Then the same methods used to measure floc volume and density should be applied in silica for fractal models. Given the chemical composition of the modelled material and the initial particle shapes and sizes, a mass value can be calculated for the volume occupied by the modelled fractal morphology. The measured and calculated densities are then compared to validate the model. Important to note that density is a complex parameter as it depends on the experimental conditions and material packing. In nanosystems density is often quantified in molecules $/ \mathrm{nm}^{3}$, not in $\mathrm{g} / \mathrm{ml}$ and can change depending on coatings (Park et al., 2004; Zhuravlev and Potapov, 2006).

The same algorithm can be applied to compare measured and modelled electro-physical parameters of surface charge, zeta-potential, etc.

In Kowalczyk et al. (2009) and Bishop et al. (2009) it was stated that the sizes of NPs likely to aggregate tend to stay within one scaling level, i.e. after reaching a certain limit larger particles loose reactivity with smaller particles, but they may be able to agglomerate with one another. A relation between scale and binding force was shown in Kalsin et al. (2006) where ordered non-compact structures were observed for larger aggregate sizes of silver and gold NPs. This demonstrates the scale selectivity of physico-chemical interactions at the nanoscale and could be another validation algorithm, in which characteristic stable aggregate sizes are compared with characteristic sizes of the hierarchical fractal models.

The values of the physico-chemical constants obtained from fractal models can then be used when solving environmental kinetics equations as input parameters and factors affecting statistical descriptors mentioned in Table 1 to achieve more accurate ENM fate predictions.

\section{Conclusions}

The critical analysis of the available ENMs environmental fate modelling approaches presented in this work confirms that existing tools do not satisfactorily reflect the complexity of relevant nanoscale aggregation phenomena. It has been shown that FM would provide a more realistic representation of NP aggregate structures, and steps to apply a fractal-based NM classification to improve existing kinetic models were proposed. A listing of descriptors from existing MMMs that can be described more accurately with FM was given. The presented approach in modelling is applicable to non-compact colloid aggregates, however fractal image analysis may be more broadly used for the detection of specific ENMs in the environment.

\section{Acknowledgement}

Authors gratefully acknowledge the European Commission for funding the FP7 MC IRSES project ECONANOSORB [grant number PIRSES-GA-2011-295260]. 


\section{References}

Arvidsson, R., Molander, S., Sandèn, B., Hassellov, M., 2011. Challenges in exposure modeling of nanoparticles in aquatic environments. Hum. Ecol. Risk. Assess. 17, 245-262.

Avilov, S.V., Zhukalin, D.A., Bitutskaya, L.A., Domashevskaya, E.P., 2014. 3-D modelling of fractal nanoclusters using the iterated affine transformations systems method. Recent Advances in Mathematics, Statistics and Economics, pp. 128-130 Presented at the Pure Mathematics - Applied Mathematics (PM-AM'14), Venice, Italy.

Barnsley, M.F., 1988. In: Peitgen, H.-O., Saupe, D. (Eds.), The Science of Fractal Images. Springer-Verlag New York, Inc., New York, NY, USA, pp. 219-242.

Barnsley, M.F., Demko, S., 1985. Iterated function systems and the global construction of fractals. Proc. R. Soc. Lond. Math. Phys. Sci. 399:243-275. http://dx.doi.org/10.1098/ rspa.1985.0057.

Bishop, K.J.M., Wilmer, C.E., Soh, S., Grzybowski, B.A., 2009. Nanoscale forces and their uses in self-assembly. Small 5, 1600-1630.

Bitutskaya, L.A., Golovinsky, P.A., Zhukalin, D.A., Alexeeva, E.V., Avilov, S.V., Lukin, A.N 2013. Fractal coagulation of polydisperse hydrated mineral systems doped by CNTs. Condens. Math. Intell. 15, 59-64.

Bokeloh, M., Wand, M., Seidel, H.-P., 2010. A connection between partial symmetry and inverse procedural modeling. ACM SIGGRAPH 2010 Papers, SIGGRAPH'10. ACM, New York, NY, USA:pp. 104:1-104:10 http://dx.doi.org/10.1145/1833349.1778841.

Brasil, A.M., Farias, T.L., Carvalho, M.G., Koylu, U.O., 2001. Numerical characterization of the morphology of aggregated particles. J. Aerosol Sci. 32:489-508. http://dx.doi. org/10.1016/S0021-8502(00)00097-5.

Browne, K.P., Grzybowski, B.A., 2011. Controlling the properties of self-assembled monolayers by substrate curvature†. Langmuir 27:1246-1250. http://dx.doi.org/10.1021/ la103960q.

Buffle, J., Wilkinson, K.J., Stoll, S., Filella, M., Zhang, J., 1998. A generalized description of aquatic colloidal interactions: the three-colloidal component approach. Environ. Sci. Technol. 32:2887-2899. http://dx.doi.org/10.1021/es980217h.

Cai, J., Hu, X., Xiao, B., Zhou, Y., Wei, W., 2017. Recent developments on fractal-based approaches to nanofluids and nanoparticle aggregation. Int. J. Heat Mass Transf. 105: 623-637. http://dx.doi.org/10.1016/j.ijheatmasstransfer.2016.10.011.

Canesi, L., Corsi, I., 2016. Effects of nanomaterials on marine invertebrates. Sci. Total Environ. 565:933-940. http://dx.doi.org/10.1016/j.scitotenv.2016.01.085.

Captur, G., Karperien, A.L., Li, C., Zemrak, F., Tobon-Gomez, C., Gao, X., Bluemke, D.A., Elliott, P.M., Petersen, S.E., Moon, J.C., 2015. Fractal frontiers in cardiovascular magnetic resonance: towards clinical implementation. J. Cardiovasc. Magn. Reson. 17. http://dx.doi.org/10.1186/s12968-015-0179-0.

Chekli, L., Zhao, Y.X., Tijing, L.D., Phuntsho, S., Donner, E., Lombi, E., Gao, B.Y., Shon, H.K., 2015. Aggregation behaviour of engineered nanoparticles in natural waters: characterising aggregate structure using on-line laser light scattering. J. Hazard. Mater. 284:190-200. http://dx.doi.org/10.1016/j.jhazmat.2014.11.003.

Chowdhury, I., Walker, S.L., Mylon, S.E., 2013. Aggregate morphology of nano-TiO2: role of primary particle size, solution chemistry, and organic matter. Environ. Sci.-Process. Impacts:275-282 http://dx.doi.org/10.1039/c2em30680h.

Collet, P., Lutton, E., Raynal, F., Schoenauer, M., 2000. Polar IFS + parisian genetic programming $=$ efficient IFS inverse problem solving. Genet. Program Evolvable Mach. 1:339-361. http://dx.doi.org/10.1023/A:1010065123132.

Crownover, R.M., 1995. Introduction to Fractals and Chaos. Jones and Bartlett books in mathematics, Jones and Bartlett.

Dale, A.L., Casman, E.A., Lowry, G.V., Lead, J.R., Viparelli, E., Baalousha, M., 2015. Modeling nanomaterial environmental fate in aquatic systems. Environ. Sci. Technol. 49: 2587-2593. http://dx.doi.org/10.1021/es505076w.

Dale, A.L., Lowry, G.V., Casman, E.A., 2013. Modeling nanosilver transformations in freshwater sediments. Environ. Sci. Technol. 47:12920-12928. http://dx.doi.org/10.1021/ es402341t.

Docter, D., Distler, U., Storck, W., Kuharev, J., Wünsch, D., Hahlbrock, A., Knauer, S.K. Tenzer, S., Stauber, R.H., 2014. Quantitative profiling of the protein coronas that form around nanoparticles. Nat. Protoc. 9:2030-2044. http://dx.doi.org/10.1038/ nprot.2014.139.

Docter, D., Westmeier, D., Markiewicz, M., Stolte, S., Knauer, S.K., Stauber, R.H., 2015. The nanoparticle biomolecule corona: lessons learned - challenge accepted? Chem. Soc. Rev. 44:6094-6121. http://dx.doi.org/10.1039/C5CS00217F.

Du, J.-X., Zhai, C.-M., Wang, Q.-P., 2012. Recognition of leaf image based on outline and vein fractal dimension feature. In: Huang, D.-S., Gan, Y., Bevilacqua, V., Figueroa, J. (Eds.), Advanced Intelligent Computing. Lecture Notes in Computer Science. Springer, Berlin Heidelberg, pp. 364-369.

Elimelech, M., Gregory, J., Jia, X., Williams, R.A., Gregory, J., Jia, X., Williams, R.A., 1995a. Chapter 15 - application of simulation techniques to colloidal dispersion systems. In: Elimelech, M., Gregory, J., Jia, X., Williams, R.A., Gregory, J., Jia, X., Williams, R.A. (Eds.), Particle Deposition \& Aggregation. Butterworth-Heinemann, Woburn, pp. $402-425$

Elimelech, M., Gregory, J., Jia, X., Williams, R.A., Gregory, J., Jia, X., Williams, R.A., 1995b. Chapter 6 - modelling of aggregation processes. In: Elimelech, M., Gregory, J., Jia, X., Williams, R.A., Gregory, J., Jia, X., Williams, R.A. (Eds.), Particle Deposition \& Aggregation. Butterworth-Heinemann, Woburn, pp. 157-202.

Feder, J., 1988. Fractals. Springer, Physics of Solids and Liquids.

Ferreiro, N., Giorgi, A., Feijoó, C., 2013. Effects of macrophyte architecture and leaf shape complexity on structural parameters of the epiphytic algal community in a Pampean stream. Aquat. Ecol. 47:389-401. http://dx.doi.org/10.1007/s10452-013-9452-1.

Frenklach, M., Ahmadi, G., Pierre, P., 2009. Modeling and Computation of Nanoparticles in Fluid Flows. p. 358.

Friedlander, S.K., 2000. Smoke, Dust, and Haze: Fundamentals of Aerosol Dynamics, 59New York: Oxford University Press.
Ganin, A.A., Bitutskaya, L.A., Bormontov, E.N., 2014. Electronic structure of two isomers of fluorine derivatives of single-walled carbon nanotubes of C2F stoichiometry within the density functional theory. Recent Advances in Biomedical \& Chemical Engineering and Materials Science, pp. 92-96 Presented at the Chemical Engineering and Materials Science (CEMS'14), Venice, Italy.

Garner, K.L., Keller, A.A., 2014. Emerging patterns for engineered nanomaterials in the environment: a review of fate and toxicity studies. J. Nanopart. Res.:16 http://dx.doi. org/10.1007/s11051-014-2503-2.

Gmachowski, L., 2002. Calculation of the fractal dimension of aggregates. Colloids Surf. A Physicochem. Eng. Asp. 211:197-203. http://dx.doi.org/10.1016/S09277757(02)00278-9.

Godinez, I.G., Darnault, C.J.G., 2011. Aggregation and transport of nano-TiO2 in saturated porous media: effects of $\mathrm{pH}$, surfactants and flow velocity. Water Res. 45:839-851. http://dx.doi.org/10.1016/j.watres.2010.09.013.

Gottschalk, F., Lassen, C., Kjoelholt, J., Christensen, F., Nowack, B., 2015. Modeling flows and concentrations of nine engineered nanomaterials in the danish environment Int. J. Environ. Res. Public Health 12:5581-5602. http://dx.doi.org/10.3390/ ijerph120505581.

Gottschalk, F., Scholz, R.W., Nowack, B., 2010. Probabilistic material flow modeling for assessing the environmental exposure to compounds: methodology and an application to engineered nano-TiO2 particles. Environ. Model. Softw. 25:320-332. http:// dx.doi.org/10.1016/j.envsoft.2009.08.011.

Gottschalk, F., Sonderer, T., Scholz, R., Nowack, B., 2009. modelled environmental concentrations of engineered nanomaterials (TiO2, ZnO, Ag, CNT, Fullerenes) for different regions. Env. Sci. Technol. 43, 9216-9222.

Graham, B.P., van Ooyen, A., 2001. Compartmental models of growing neurites Neurocomputing 38-40:31-36. http://dx.doi.org/10.1016/S0925-2312(01)00463-5.

Grasso, D., Subramaniam, K., Butkus, M., Strevett, K., Bergendahl, J., 2002. A review of nonDLVO interactions in environmental colloidal systems. Rev. Environ. Sci. Biotechnol. 1:17-38. http://dx.doi.org/10.1023/A:1015146710500.

Gröller, E., 1994. Modeling and rendering of nonlinear iterated function systems. Comput Graph. 18, 739-748.

Hagerhall, C.M., Purcell, T., Taylor, R., 2004. Fractal dimension of landscape silhouette outlines as a predictor of landscape preference. J. Environ. Psychol. 24:247-255. http:// dx.doi.org/10.1016/j.jenvp.2003.12.004.

Hart, J.C., 1996. Fractal image compression and recurrent iterated function systems. IEEE Comput. Graph. Appl. 16, 25-33.

Hart, J.C., Cochran, W.O., Flynn, P.J., 1997. Similarity hashing: a computer vision solution to the inverse problem of linear fractals. Fractals 05, 39-50. doi:10.1142 S0218348X97000620

Hassellov, M., Readman, J., Rabville, J., Tiede, K., 2008. Nanoparticle analysis and characterization methodologies in environmental risk assessment of engineered nanoparticles. Ecotoxicology 17, 344-361.

Healy, T.W., White, L.R., 1978. Ionizable surface group models of aqueous interfaces. Adv. Colloid Interf. Sci. 9:303-345. http://dx.doi.org/10.1016/0001-8686(78)85002-7.

Hendren, C.O., Mesnard, X., Dröge, J., Wiesner, M.R., 2011. Estimating production data for five engineered nanomaterials as a basis for exposure assessment. Environ. Sci. Technol. 45:2562-2569. http://dx.doi.org/10.1021/es103300g.

Ho Moon, Y., Soon Kim, H., Shin Kim, Y., Ho Kim, J., 1999. A novel fast fractal decoding algorithm. Signal Process. Image Commun. 14:325-333. http://dx.doi.org/10.1016/ S0923-5965(98)00016-2.

Hristozov, D., MacCalman, L., Jensen, K.A., Stone, V., Scott-Fordsmand, J., Nowack, B., Fernandes, T., Marcomini, A., 2013. Risk assessment of engineered nanomaterials: state of the art and roadmap for future research. In: Monteiro-Riviere, N.A., Tran, L (Eds.), Nanotoxicology: Progress Towards Nanomedicine Informa Healthcare.

Inci, G., Arnold, A., Kronenburg, A., Weeber, R., 2014. Modeling nanoparticle agglomeration using local interactions. Aerosol Sci. Technol. 48, 842-852.

ISO, 2012. TC 229: Nanotechnologies - Guidance on physico-chemical characterization of engineered nanoscale materials for toxicologic assessment.

Ivanov, V.V., Talanov, V.M., 2013. Construction of fractal nanostructures based on Kepler-Shubnikov nets. Crystallogr. Rep. 58:383-392. http://dx.doi.org/10. 1134/S1063774513030073.

Jayasuriya, S.A., Liew, A.W.C., Law, N.F., 2013. Brain symmetry plane detection based on fractal analysis. Comput. Med. Imaging Graph. 37:568-580. http://dx.doi.org/10. 1016/j.compmedimag.2013.06.001.

Jelinek, H.F., Milošević, N.T., Karperien, A., Krstonošić, B., 2013. Box-counting and multifractal analysis in neuronal and glial classification. Adv. Intell. Syst. Comput.: 177-189 187 AISC. 10.1007/978-3-642-32548-9-13.

Ju, T., Schaefer, S., Goldman, R., 2004. Recursive turtle programs and iterated affine transformations. Comput. Graph. 28:991-1004. http://dx.doi.org/10.1016/j.cag.2004.08.016.

Jun, Y.-S., Kim, D., Neil, C.W., 2016. Heterogeneous nucleation and growth of nanoparticles at environmental interfaces. Acc. Chem. Res. 49:1681-1690. http://dx.doi.org/10. 1021/acs.accounts.6b00208.

Kaandorp, J.A., 1994. Fractal Modelling: Growth and Form in Biology. Springer-Verlag New York, Inc., New York, NY, USA.

Kalsin, A.M., Fialkowski, M., Paszewski, M., Smoukov, S.K., Bishop, K.J.M., Grzybowski, B.A., 2006. Electrostatic self-assembly of binary nanoparticle crystals with a diamond-like lattice. Science 312:420-424. http://dx.doi.org/10.1126/science.1125124.

Karam, H., Nakajima, M., 2001. Towards realistic modeling and rendering of 3-D escapetime deterministic fractal shapes, in: Seventh International Conference on Virtual Systems and Multimedia, 2001. Proceedings. Presented at the Seventh International Conference on Virtual Systems and Multimedia, 2001. Proceedings:pp. 565-574 http://dx.doi.org/10.1109/VSMM.2001.969714.

Karperien, A., Ahammer, H., Jelinek, H.F., 2013. Quantitating the subtleties of microglial morphology with fractal analysis. Front. Cell. Neurosci. 7. http://dx.doi.org/10.3389/ fncel.2013.00003. 
Keller, A.A., Lazareva, A., 2014. Predicted releases of engineered nanomaterials: from global to regional to local. Environ. Sci. Technol. Lett. 1:65-70. http://dx.doi.org/10.1021/ ez400106t.

Kimori, Y., Katayama, E., Morone, N., Kodama, T., 2011. Fractal dimension analysis an mathematical morphology of structural changes in actin filaments imaged by electron microscopy. J. Struct. Biol. 176:1-8. http://dx.doi.org/10.1016/j.jsb.2011.07.007.

Klaine, S.J., Alvarez, P.J.J., Batley, G.E., Fernandes, T.F., Handy, R.D., Lyon, D.Y., Mahendra, S. McLaughlin, M.J., Lead, J.R., 2008. Nanomaterials in the environment: behavior, fate, bioavailability, and effects. Environ. Toxicol. Chem. 27:1825-1851. http://dx.doi.org/ 10.1897/08-090.1.

Kler, S., Wang, J.C.-Y., Dhason, M., Oppenheim, A., Zlotnick, A., 2013. Scaffold properties are a key determinant of the size and shape of self-assembled virus-derived particles. ACS Chem. Biol. 8:2753-2761. http://dx.doi.org/10.1021/cb4005518.

Kong, Y.L., Muniandy, S.V., Fakir, M.S., Sulaiman, K., 2014. Morphological image interpretation of organic nickel(II) phthalocyanine-tetrasulfonic acid tetrasodium film using fractal analysis. Appl. Surf. Sci. 301:363-368. http://dx.doi.org/10.1016/j.apsusc. 2014.02.081.

Kowalczyk, B., Kalsin, A.M., Orlik, R., Bishop, K.J.M., Patashinskii, A.Z., Mitus, A., Grzybowski, B.A., 2009. Size selection during crystallization of oppositely charged nanoparticles. Chem. Eur. J. 15:2032-2035. http://dx.doi.org/10.1002/chem.200802334.

Kowalczyk, B., Lagzi, I., Grzybowski, B.A., 2011. Nanoseparations: Strategies for size and/or shape-selective purification of nanoparticles. Curr. Opin. Colloid Interface Sci. 16: 135-148. http://dx.doi.org/10.1016/j.cocis.2011.01.004.

Köylü, Ü.Ö., Faeth, G.M., Farias, T.L., Carvalho, M.G., 1995. Fractal and projected structure properties of soot aggregates. Combust. Flame 100:621-633. http://dx.doi.org/10. 1016/0010-2180(94)00147-K.

Li, B., Cao, F., Wan, Z., Feng, Z., Zheng, H., 2016. Fractal aggregation and breakup of fine particles. Therm. Sci. 20:797-801. http://dx.doi.org/10.2298/TSCI1603797L.

Lin, C.-H., Chen, J.-L., Gaing, Z.-L., 2010a. Combining biometric fractal pattern and particle swarm optimization-based classifier for fingerprint recognition. Math. Probl. Eng. 2010, e328676. http://dx.doi.org/10.1155/2010/328676

Lin, D., Tian, X., Wu, F., Xing, B., 2010b. Fate and transport of engineered nanomaterials in the environment. J. Environ. Qual. 39:1896. http://dx.doi.org/10.2134/jeq2009.0423.

Lin, S., Wiesner, M.R., 2012. Theoretical investigation on the interaction between a soft particle and a rigid surface. Chem. Eng. J. 191:297-305. http://dx.doi.org/10.1016/j. cej.2012.03.019.

Linsinger, T., Roebben, G., Gilliland, D., Calzolai, L., Rossi, F., Gibson, N., Klein, C., 2012. Requirements on measurements for the implementation of the European Commission definition of the term "nanomaterial" (Reference report of the Joint Research Centre No. JRC73260). Reference report of the Joint Research Centre. publication office of the European Union, Luxembourg.

Liu, H.H., Cohen, Y., 2014. Multimedia environmental distribution of engineered nanomaterials. Environ. Sci. Technol. 48:3281-3292. http://dx.doi.org/10.1021/ es405132z.

Loosli, F., Le Coustumer, P., Stoll, S., 2013. TiO2 nanoparticles aggregation and disaggregation in presence of alginate and Suwannee River humic acids. $\mathrm{pH}$ and concentration effects on nanoparticle stability. Water Res. 47:6052-6063. http://dx.doi.org/10. 1016/j.watres.2013.07.021.

López-López, J.M., Schmitt, A., Moncho-Jordá, A., Hidalgo-Álvarez, R., 2006. Stability of binary colloids: kinetic and structural aspects of heteroaggregation processes. Soft Matter 2:1025-1042. http://dx.doi.org/10.1039/B608349H.

Lord, E.A., Mackay, A.L., Ranganathan, S., 2006. New Geometries for New Materials. Cambridge University Press.

Maggi, F., 2009. Biological flocculation of suspended particles in nutrient-rich aqueous ecosystems. J. Hydrol. 376:116-125. http://dx.doi.org/10.1016/j.jhydrol.2009.07.040.

Mandelbrot, B.B., 1983. The Fractal Geometry of Nature Henry Holt and Company.

Mandelbrot, B.B., 1986. Self-affine fractal sets, I: the basic fractal dimensions A2 - Pietronero, Luciano. In: TOSATTI, E. (Ed.), Fractals in Physics. Elsevier, Amsterdam, pp. 3-15.

Mandelbrot, B.B., 1992. Plane DLA is not self-similar; is it a fractal that becomes increasingly compact as it grows? Phys. Stat. Mech. Its Appl. 191:95-107. http://dx.doi. org/10.1016/0378-4371(92)90511-N.

Martyn, T., 2010. Realistic rendering 3D IFS fractals in real-time with graphics accelerators Comput. Graph. Pergamon 34:167-175. http://dx.doi.org/10.1016/j.cag.2009.10.001.

Meesters, J.A., Veltman, K., Hendriks, A.J., van de Meent, D., 2013. Environmental exposure assessment of engineered nanoparticles: why REACH needs adjustment. Integr. Environ. Assess. Manag. 9:e15-e26. http://dx.doi.org/10.1002/ieam.1446.

Meesters, J.A.J., Koelmans, A.A., Quik, J.T.K., Hendriks, A.J., van de Meent, D., 2014. Multimedia modeling of engineered nanoparticles with SimpleBox4nano: model definition and evaluation. Environ. Sci. Technol. 48:5726-5736. http://dx.doi.org/10.1021/es500548h.

Meng, Z., Hashmi, S.M., Elimelech, M., 2013. Aggregation rate and fractal dimension of fullerene nanoparticles via simultaneous multiangle static and dynamic light scattering measurement. J. Colloid Interface Sci. 392:27-33. http://dx.doi.org/10.1016/j.jcis. 2012.09.088.

Mishin, M.V., Zamotin, K.Y., Protopopova, V.S., Alexandrov, S.E., 2015. Chain assemblies from nanoparticles synthesized by atmospheric pressure plasma enhanced chemical vapor deposition: the computational view. J. Nanosci. Nanotechnol. 15:9966-9974. http://dx.doi.org/10.1166/jnn.2015.11043.

Mohammadi, S., Rashidi, F., Mousavi-Dehghani, S.A., Ghazanfari, M.-H., 2016. Modeling of asphaltene aggregation phenomena in live oil systems at high pressure-high temperature. Fluid Phase Equilib. 423:55-73. http://dx.doi.org/10.1016/j.fluid.2016.04.010.

Mueller, N.C., Nowack, B., 2008. Exposure modeling of engineered nanoparticles in the environment. Environ. Sci. Technol. 42:4447-4453. http://dx.doi.org/10.1021/ es7029637.

Nasser, F., Lynch, I., 2016. Secreted protein eco-corona mediates uptake and impacts of polystyrene nanoparticles on Daphnia magna. J. Proteome 137:45-51. http://dx.doi. org/10.1016/j.jprot.2015.09.005.
Neil, C.W., Ray, J.R., Lee, B., Jun, Y.-S., 2016. Fractal aggregation and disaggregation of newly formed iron(III) (Hydr)oxide nanoparticles in the presence of natural organic matter and arsenic. Env. Sci Nano. http://dx.doi.org/10.1039/C5EN00283D.

Neil, G., Curtis, K.M., 1997. Shape recognition using fractal geometry. Pattern Recogn. 30: 1957-1969. http://dx.doi.org/10.1016/S0031-3203(96)00193-8.

Nikiel, S., 2007. nD iterated function systems and their applications. Iterated Function Systems for Real-Time Image Synthesis. Springer, London, pp. 99-131.

Ono-Ogasawara, M., Serita, F., Takaya, M., 2009. Distinguishing nanomaterial particles from background airborne particulate matter for quantitative exposure assessment. J. Nanopart. Res. 11:1651-1659. http://dx.doi.org/10.1007/s11051-009-9703-1.

Pal, S., Tak, Y.K., Song, J.M., 2007. Does the antibacterial activity of silver nanoparticles depend on the shape of the nanoparticle? A study of the gram-negative bacterium Escherichia coli. Appl. Environ. Microbiol. 73:1712-1720. http://dx.doi.org/10.1128/ AEM.02218-06.

Papanicolaou, A.N.(.T.)., Tsakiris, A.G., Strom, K.B., 2012. The use of fractals to quantify the morphology of cluster microforms. Geomorphology 139-140:91-108. http://dx.doi. org/10.1016/j.geomorph.2011.10.007.

Park, K., Kittelson, D., Zachariah, M., McMurry, P., 2004. Measurement of inherent material density of nanoparticle agglomerates. J. Nanopart. Res. 6:267-272. http://dx.doi.org/ 10.1023/B:NANO.0000034657.71309.e6.

Patil, A.J., Mann, S., 2008. Bio-inorganic nanohybrids based on organoclay self-assembly. BioInorganic Hybrid Nanomaterials. Wiley-VCH Verlag GmbH \& Co. KGaA, pp. 239-270.

Petosa, A.R., Jaisi, D.P., Quevedo, I.R., Elimelech, M., Tufenkji, N., 2010. Aggregation and deposition of engineered nanomaterials in aquatic environments: role of physicochemical interactions. Environ. Sci. Technol. 44:6532-6549. http://dx.doi.org/10.1021/es100598h.

Pia, G., Siligardi, C., Casnedi, L., Sanna, U., 2016. Pore size distribution and porosity influence on sorptivity of ceramic tiles: from experimental data to fractal modelling. Ceram. Int. 42:9583-9590. http://dx.doi.org/10.1016/j.ceramint.2016.03.041.

Piccinno, F., Gottschalk, F., Seeger, S., Nowack, B., 2012. Industrial production quantities and uses of ten engineered nanomaterials in Europe and the world. J. Nanopart. Res. http://dx.doi.org/10.1007/s11051-012-1109-9.

Pippa, N., Dokoumetzidis, A., Demetzos, C., Macheras, P., 2013. On the ubiquitous presence of fractals and fractal concepts in pharmaceutical sciences: a review. Int. J. Pharm. 456:340-352. http://dx.doi.org/10.1016/j.ijpharm.2013.08.087.

Praetorius, A., Arvidsson, R., Molander, S., Scheringer, M., 2013. Facing complexity through informed simplifications: a research agenda for aquatic exposure assessment of nanoparticles. Env. Sci Process. Impacts 15:161-168. http://dx.doi.org/10.1039/ C2EM30677H.

Praetorius, A., Scheringer, M., Hungerbühler, K., 2012. Development of environmental fate models for engineered nanoparticles-a case study of tio2 nanoparticles in the Rhine river. Environ. Sci. Technol. 46:6705-6713. http://dx.doi.org/10.1021/es204530n.

Quik, J.T.K., Vonk, J.A., Hansen, S.F., Baun, A., Van De Meent, D., 2011. How to assess exposure of aquatic organisms to manufactured nanoparticles? Environ. Int. 37: 1068-1077. http://dx.doi.org/10.1016/j.envint.2011.01.015.

Ruiz-Hitzky, E., Darder, M., Aranda, P., 2008. An introduction to bio-nanohybrid materials. Bio-Inorganic Hybrid Nanomaterials. Wiley-VCH Verlag GmbH \& Co. KGaA, pp. 1-40.

Sani-Kast, N., Scheringer, M., Slomberg, D., Labille, J., Praetorius, A., Ollivier, P., Hungerbühler, K., 2015. Addressing the complexity of water chemistry in environmental fate modeling for engineered nanoparticles. Sci. Total Environ. 535: 150-159. http://dx.doi.org/10.1016/j.scitotenv.2014.12.025.

Saunders, R.W., Plane, J.M.C., 2006. Fractal growth modelling of nanoparticles. J. Aerosol Sci. 37:1737-1749. http://dx.doi.org/10.1016/j.jaerosci.2006.08.007.

SCENIHR (Scientific Committee on Emerging and Newly Identified Health Risks), 2006. Opinion on the Appropriateness of Existing Methodologies to Assess the Potential Risks Associated with Engineered and Adventitious Products of Nanotechnology. 10 March 2006. http://ec.europa.eu/health/ph_risk/committees/04_scenihr/docs/ scenihr_o 003b.pdf.

Shevchenko, V.Y., Mackay, A.L., 2011. Geometrical principles of the self-assembly of nanoparticles. Glas. Phys. Chem. 34:1-8. http://dx.doi.org/10.1134/S108765960801001X.

Sithebe, N., Nkhalambayausi Chirwa, E., 2016. Mechanistic flocculation model incorporating the fractal properties of settling particles. J. Environ. Eng. 142:04016027. http:// dx.doi.org/10.1061/(ASCE)EE.1943-7870.0001096.

Smith, B.M., Pike, D.J., Kelly, M.O., Nason, J.A., 2015. Quantification of heteroaggregation between citrate-stabilized gold nanoparticles and hematite colloids. Environ. Sci. Technol. 49:12789-12797. http://dx.doi.org/10.1021/acs.est.5b03486.

Smith, J., Lange, G.D., Marks, W.B., 1996. Fractal methods and results in cellular morphology - dimensions, lacunarity and multifractals. J. Neurosci. Methods 69:123-136. http://dx.doi.org/10.1016/S0165-0270(96)00080-5.

Smith Jr., T.G., Marks, W.B., Lange, G.D., Sheriff Jr., W.H., Neale, E.A., 1989. A fractal analysis of cell images. J. Neurosci. Methods 27:173-180. http://dx.doi.org/10.1016/01650270(89)90100-3.

Smoluchowski, M.V., 1917. Grundriß der Koagulationskinetik kolloider Lösungen. Kolloid-Z. 21:98-104. http://dx.doi.org/10.1007/BF01427232.

Solla-Gullón, J., Vidal-Iglesias, F.J., López-Cudero, A., Garnier, E., Feliu, J.M., Aldaz, A., 2008. Shape-dependent electrocatalysis: methanol and formic acid electrooxidation on preferentially oriented Pt nanoparticles. Phys. Chem. Chem. Phys. 10:3689. http:// dx.doi.org/10.1039/b802703j.

Sterling, M.C., Bonner, J.S., Ernest, A.N.S., Page, C.A., Autenrieth, R.L., 2005. Application of fractal flocculation and vertical transport model to aquatic sol-sediment systems. Water Res. 39:1818-1830. http://dx.doi.org/10.1016/j.watres.2005.02.007.

Stolpe, B., Hassellöv, M., 2007. Changes in size distribution of fresh water nanoscale colloidal matter and associated elements on mixing with seawater. Geochim. Cosmochim. Acta 71:3292-3301. http://dx.doi.org/10.1016/j.gca.2007.04.025.

Stone, V., Pozzi-Mucelli, S., Tran, L., Aschberger, K., Sabella, S., Vogel, U., Poland, C., Balharry, D., Fernandes, T., Gottardo, S., Hankin, S., Hartl, M.G., Hartmann, N. Hristozov, D., Hund-Rinke, K., Johnston, H., Marcomini, A., Panzer, O., Roncato, D., 
Saber, A.T., Wallin, H., Scott-Fordsmand, J.J., 2014. ITS-NANO - prioritising nanosafety research to develop a stakeholder driven intelligent testing strategy. Part. Fibre Toxicol. 11:9. http://dx.doi.org/10.1186/1743-8977-11-9.

Tiede, K., Boxall, A.B.A., Wang, X., Gore, D., Tiede, D., Baxter, M., David, H., Tear, S.P., Lewis, J., 2010. Application of hydrodynamic chromatography-ICP-MS to investigate the fate of silver nanoparticles in activated sludge. J. Anal. At. Spectrom. 25, 1149-1154.

Tuchin, A.V., Ganin, A.A., Bitutskaya, L.A., Bormontov, E.N., 2014. A theoretical study of an electronic structure of the infinite and finite- length carbon nanotubes. Recent Advances in Biomedical \& Chemical Engineering and Materials Science, pp. 40-46 Presented at the Chemical Engineering and Materials Science (CEMS'14), Venice, Italy.

Tuoriniemi, J., Cornelis, G., Hassellöv, M., 2012. Size discrimination and detection capabilities of single-particle ICPMS for environmental analysis of silver nanoparticles. Anal. Chem. 84:3965-3972. http://dx.doi.org/10.1021/ac203005r.

Van Leeuwen, C., Vermeire, T., 2007. Risk Assessment of Chemicals: An Introduction. Springer, Dordrecht.

Walker, D.A., Browne, K.P., Kowalczyk, B., Grzybowski, B.A., 2010a. Self-assembly of nanotriangle superlattices facilitated by repulsive electrostatic interactions. Angew. Chem. Int. Ed. 49:6760-6763. http://dx.doi.org/10.1002/anie.201002558.

Walker, D.A., Kowalczyk, B., de la Cruz, M.O., Grzybowski, B.A., 2011. Electrostatics at thenanoscale. Nanomedicine 3:1316-1344. http://dx.doi.org/10.1039/C0NR00698J.

Walker, D.A., Leitsch, E.K., Nap, R.J., Szleifer, I., Grzybowski, B.A., 2013. Geometric curvature controls the chemical patchiness and self-assembly of nanoparticles. Nat. Nanotechnol. 8:676-681. http://dx.doi.org/10.1038/nnano.2013.158.

Walker, D.A., Wilmer, C.E., Kowalczyk, B., Bishop, K.J.M., Grzybowski, B.A., 2010b. Precision assembly of oppositely and like-charged nanoobjects mediated by charge-induced dipole interactions. Nano Lett. 10:2275-2280. http://dx.doi.org/10.1021/ nl1012079.

Wang, B.-X., Zhou, L.-P., Peng, X.-F., 2003. A fractal model for predicting the effective thermal conductivity of liquid with suspension of nanoparticles. Int. J. Heat Mass Transf. 46:2665-2672. http://dx.doi.org/10.1016/S0017-9310(03)00016-4.
Wang, D., Nap, R.J., Lagzi, I., Kowalczyk, B., Han, S., Grzybowski, B.A., Szleifer, I., 2011. How and why nanoparticle's curvature regulates the apparent pka of the coating ligands. J. Am. Chem. Soc. 133:2192-2197. http://dx.doi.org/10.1021/ja108154a.

Wiesner, M.R., 1992. Kinetics of aggregate formation in rapid mix. Water Res. 26: 379-387. http://dx.doi.org/10.1016/0043-1354(92)90035-3.

Witten, T.A., Sander, L.M., 1981. Diffusion-limited aggregation, a kinetic critical phenomenon. Phys. Rev. Lett. 47:1400-1403. http://dx.doi.org/10.1103/PhysRevLett.47.1400

Xiaoqing, H., Oin, Z., Wenbo, L., 2013. A new method for image retrieval based on analyzing fractal coding characters. J. Vis. Commun. Image Represent. 24:42-47. http://dx. doi.org/10.1016/j.jvcir.2012.10.005.

Xu, H., Jiao, R., Xiao, F., Wang, D., 2014. Effects of different coagulants in treatment of TiO2-humic acid (HA) water and the aggregate characterization in different coagulation conditions. Colloids Surf. A Physicochem. Eng. Asp. 446:213-223. http://dx.doi. org/10.1016/j.colsurfa.2014.01.028.

Xu, R., Wang, D., Zhang, J., Li, Y., 2006. Shape-dependent catalytic activity of silver nanoparticles for the oxidation of styrene. Chem. Asian. J. 1:888-893. http://dx.doi.org/10. 1002/asia.200600260.

Zhang, W., 2014. Nanoparticle aggregation: principles and modeling. In: Capco, D.G., Chen, Y. (Eds.), Nanomaterial, Advances in Experimental Medicine and Biology. Springer, Netherlands, pp. 19-43.

Zhukalin, D.A., Tuchin, A.V., Avilov, S.V., Bitutskaya, L.A., Bormontov, E.N., 2014. Charge properties and fractal aggregation of carbon nanotubes. Recent Advances in Biomedical \& Chemical Engineering and Materials Science, pp. 79-81 Presented at the Chemical Engineering and Materials Science (CEMS'14), Venice, Italy.

Zhuravlev, L.T., Potapov, V.V., 2006. Density of silanol groups on the surface of silica precipitated from a hydrothermal solution. Russ. J. Phys. Chem. 80:1119-1128. http://dx doi.org/10.1134/S0036024406070211. 